\title{
THE PREVALENCE OF COMBINED PRO-THROMBOTIC POLYMORPHISMS IN PATIENTS WITH RECURRENT DEEP VEIN THROMBOSIS - DOES GENETIC TESTING PROVIDE ANY BENEFIT?
}

\author{
Alicja Krejner', Malgorzata Litwiniuk ${ }^{1,2,3}$, Iwona Radziejewska-Choma ${ }^{4}$, \\ Krystyna Twardowska-Saucha ${ }^{5}$, Tomasz Grzela1,4
}

'Department of Histology and Embryology, Medical University of Warsaw, Warsaw, Poland 2Department of Otolaryngology, Medical University of Warsaw, Warsaw, Poland 3Postgraduate School of Molecular Medicine, Medical University of Warsaw, Warsaw, Poland ${ }^{4}$ NASMED-Clinic of Phlebology, Warsaw, Poland

${ }^{5}$ Medservice, Specialistic Outpatient Clinic, Zabrze, Poland
ORIGINAL PAPER

Phlebological Review 2015; 23, 1: 14-19 DOI: $10.5114 /$ pr.2015.51627

Submitted: 31.10 .2014

Accepted: 05.03.2015

\section{ADDRESS FOR CORRESPONDENCE}

Tomasz Grzela

Department of Histology and Embryology

Medical University of Warsaw

Chałubińskiego 5

02-004 Warsaw, Poland

e-mail: tomekgrzela@gmail.com

\section{INTRODUCTION}

Deep vein thrombosis (DVT) constitutes a serious clinical, social, and economic problem. Besides the cases that are sometimes misdiagnosed, DVT may also display a subclinical course, with pulmonary embolism, a serious life threatening complication, as the only clinical manifestation of the disease [1]. In that form, even if properly treated, thromboembolism is still associated with a high mortality rate of up to 15\% [2]. As well as of serious death risk, DVT may also result in permanent failure of valves in the deep vein system, with highly arduous long-term consequences: severe leg oedema, develop- ment of post-thrombotic syndrome, and leg ulceration. Thus, in addition to the direct cost of DVT treatment, the mentioned complications create significant costs for the budget of a healthcare system [3]. Moreover, they strongly affect the professional and social activity of the patient. Therefore, an effective prophylaxis of DVT and its complications should be of great interest for management in public health.

Deep vein thrombosis may be caused by various environmental or acquired factors. They include prolonged immobilisation, injury, major surgery, orthopaedic interventions, neoplasm, oral contraceptives, or hormonal replacement therapy. However, genetic predisposition, 
known as inherited thrombophilia, is also recognised as an important risk factor of DVT $[4,5]$. It is associated with the presence of polymorphic variants of two coagulation factors: FV R506Q, better known as factor Leiden, and prothrombin (PT) G20210A [6]. Furthermore, although its role in thrombosis development is indirect and more complex, polymorphism of gene encoding for methylenetetrahydrofolate reductase (MTHFR C677T), the enzyme engaged in homocysteine metabolism, is also involved [7-9].

The current diagnostic algorithm of DVT includes ultrasound examination of the affected leg, vein compression test, and the measurement of $\mathrm{D}$-dimer concentration [10]. In that algorithm the extended assessment of blood coagulation parameters or genetic testing are not performed routinely, especially at the first DVT episode. Regrettably, they are usually omitted also in cases of recurrent DVT. This decision is very often based on the assumption that the vein thrombosis itself increases the risk of disease recurrence. Indeed, the chance of DVT recurrence within 10 years after a first episode of thrombosis is estimated at approximately $25 \%[11,12]$.

It is widely accepted that molecular screening for main thrombophilic factors among the entire population is non-reasonable statistically and economically [3, 13]. Moreover, currently there are no clear indications concerning the management of patients with diagnosed mutations/polymorphisms, especially in their heterozygous forms. On the other hand, it is plausible that genetic tests introduced as a standard procedure also in the first idiopathic DVT, at least in some cases, could provide some benefit. We hypothesise that the implementation of genetic tests in the diagnostics of vein thrombosis will enable the more precise estimation of risk of thrombosis recurrence $[11,14]$. The rationale for this idea could be verified by retrospective analysis in a group of patients with recurrent DVT. Therefore, the aim of the study was to evaluate the frequency and co-existence of three pro-thrombotic single nucleotide polymorphisms (SNPs): FV R506Q, PT G20210A, and MTHFR C677T in a group of Polish patients with two or more episodes of DVT.

\section{MATERIAL AND METHODS}

The study involved 40 individuals (24 female and 16 male, with a mean age of $52.7 \pm 13.7$ years, ranging from 26 to 89 years), with medical history of at least two episodes of DVT: both in the past, or at least one in the past and the next at present, all confirmed by ultrasound scan of the leg venous system. None of the patients had diagnosed cancer, trauma, or had undergone major surgery during the onset of the first episode of DVT; however, in 7 of 24 women from the study group, the first episode could possibly be attributed to oral hormonal therapy $[3,10,13]$. The samples for population control $(n=102)$ originated from the DNA collection of a former large population study. None of the patients from the population control was diagnosed with DVT or cancer in the past.

All patients gave informed written consent to participate in the study, which was approved by the Local Ethics Committee.

One millilitre of peripheral blood from each patient was collected in an EDTA-containing test tube. Then blood samples were subjected to genomic DNA isolation using GenElute ${ }^{\mathrm{TM}}$ Blood Genomic DNA kit (Sigma-Aldrich, St. Louis, MO, USA). The DNA samples from both groups were then used for genotyping focused on three pro-thrombotic polymorphisms: FV R506Q (rs6025), PT G20210A (rs1799963), and MTHFR C677T (rs18001133). The analysis was performed using TaqMan ${ }^{\circledR}$ SNP Genotyping Assay (Life Technologies, Carlsbad, CA, USA) with an ABI PRISM 7500 Real-Time PCR device (Applied Biosystems, Foster City, CA, USA).

\section{Statistical analysis}

The odds ratio (OR) with 95\% CI for each tested polymorphism alone or in combination was calculated. The differences between groups were tested using Fisher's exact test, with $p<0.05$ considered as statistically significant.

\section{RESULTS}

According to inclusion criteria, all patients involved in the study had a documented history of at least two episodes of DVT. The ultrasonographic examination, which was performed in all patients qualified for analysis, did not reveal any significant abnormalities in the deep vein system in 5 individuals, 9 patients showed valvular insufficiency localised only in tibial or calf intramuscular veins, and in another 15 patients the deep vein failure was limited to valvular incompetence of popliteal vein only. In 8 individuals the reflux in the deep system was detectable in both the popliteal and femoral veins. Among them, in 3 individuals, venous thrombosis was associated with pulmonary embolism in the past. In the next 3 patients the extensive deep vein damage involved the iliac vessels. Also in two of those patients pulmonary embolism had occurred in the past. Insufficiency of the superficial vein system was diagnosed in 33 of 40 patients. Nine patients from the DVT group developed at least one episode of chronic leg ulcer. The clinical data are summarised in Table 1.

In the entire group only 8 patients were previously subjected to extended analysis of blood coagulation parameters with genetic tests for factor Leiden (R506Q) and prothrombin G20210A variants. The mentioned group included all individuals $(n=5)$ who developed pulmonary embolism, 1 patient after iliac vein thrombosis, and 2 other patients with femoral vein failure. 
Table 1. Clinical characteristics of DVT patients

\begin{tabular}{|c|c|c|c|c|c|c|c|c|}
\hline \multirow{2}{*}{$\begin{array}{l}\text { Localisation of deep vein } \\
\text { damage }\end{array}$} & \multirow{2}{*}{$\begin{array}{l}\text { Symptoms } \\
\text { (with } \\
\text { number of } \\
\text { patients) }\end{array}$} & \multirow{2}{*}{$\begin{array}{l}\text { Patients } \\
\text { with } \\
\text { pulmonary } \\
\text { embolism }\end{array}$} & \multirow{2}{*}{$\begin{array}{l}\text { Patients } \\
\text { with genetic } \\
\text { tests done } \\
\text { in the past } \\
\text { (positive) }\end{array}$} & \multirow{2}{*}{$\begin{array}{l}\text { Chronic anti- } \\
\text { coagulant } \\
\text { intake }\end{array}$} & \multicolumn{4}{|c|}{ Pro-thrombotic allele patterns } \\
\hline & & & & & $\begin{array}{l}\text { wild type } \\
\text { (CC/GG/RR) }\end{array}$ & $\begin{array}{l}\text { single hete- } \\
\text { rozygote }\end{array}$ & $\begin{array}{c}2 \text { alleles } \\
\text { combination }\end{array}$ & $\begin{array}{c}3 \text { and more } \\
\text { alleles com- } \\
\text { bination }\end{array}$ \\
\hline $\begin{array}{l}\text { no visible abnormalities } \\
\text { at present }(n=5)\end{array}$ & $\mathrm{SV}_{(4)^{\prime}} \mathrm{O}_{(2)}$ & - & - & - & 4 & $\mathrm{CT}(1)$ & - & - \\
\hline $\begin{array}{l}\text { tibial or intramuscular } \\
(n=9)\end{array}$ & $\mathrm{SV}_{(5)^{\prime}} \mathrm{O}_{(7)}$ & - & - & - & 3 & $\mathrm{CT}(5)$ & $\mathrm{CT} / \mathrm{GA}(1)$ & - \\
\hline popliteal $(n=15)$ & $\begin{array}{l}\mathrm{SV}_{(13)^{\prime}} \mathrm{O}_{(14)^{\prime}} \\
\mathrm{PS}_{(8)^{\prime}} \mathrm{VLU}_{(4)}\end{array}$ & - & - & 1 & 2 & $\begin{array}{l}\mathrm{CT}(6) \\
\mathrm{RQ}(3)\end{array}$ & $\begin{array}{c}\text { Tा (1) } \\
\text { CT/RQ (1) } \\
\mathrm{QQ}(1)\end{array}$ & $\mathrm{CT} / \mathrm{QQ}(1)$ \\
\hline $\begin{array}{l}\text { popliteal and/or femoral } \\
(n=8)\end{array}$ & $\begin{array}{l}\mathrm{SV}_{(8)^{\prime}} \mathrm{O}_{(8)^{\prime}} \\
\mathrm{PS}_{(7)^{\prime}} \mathrm{VLU}_{(3)}\end{array}$ & 3 & $5(1)$ & 3 & - & $\mathrm{RQ}(1)$ & $\begin{array}{c}\mathrm{CT} / \mathrm{RQ}(3) \\
\mathrm{AA}(1) \\
\mathrm{QQ}(1)\end{array}$ & $\begin{array}{l}\mathrm{TT} / \mathrm{QQ}(1) \\
\mathrm{CT} / \mathrm{AA}(1)\end{array}$ \\
\hline iliac and femoral $(n=3)$ & $\begin{array}{l}\mathrm{SV}_{(3)^{\prime}} \mathrm{O}_{(3)^{\prime}} \\
\mathrm{PS}_{(3)^{\prime}} \mathrm{VLU}_{(2)}\end{array}$ & 2 & $3(1)$ & 2 & - & - & $\mathrm{AA}(1)$ & $\begin{array}{l}\Pi \text { / QQ (1) } \\
\Pi \text { / AA (1) }\end{array}$ \\
\hline
\end{tabular}

$N$ - no symptoms; SV - superficial veins insufficiency; O - oedema; PS - post-thrombotic syndrome; VLU - venous leg ulcer; pro-thrombotic allele combination: CT / TT - of MTHFR C677T SNP; GA / AA - of PT G20210A SNP; RQ / QQ - of FV R506Q SNP

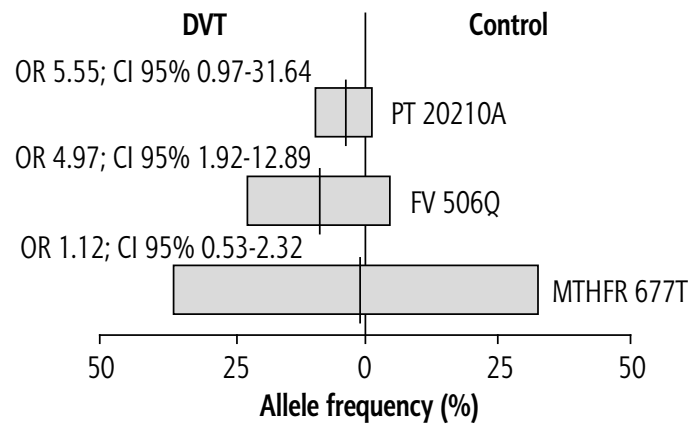

Fig. 1. The graphic presentation of frequency of main thrombophilic alleles in DVT vs. population control group. Calculated odds ratios (OR) with 95\% confidence intervals (Cl) were shown above corresponding bars, which represent a percentage of specified pro-thrombotic alleles. The vertical lines correspond to calculated means of percentages, indicating the group with allele predominance

Interestingly, in that analysis a heterozygous Leiden pattern was detected only in two of the tested samples. Our reassessment confirmed both previously identified Leiden heterozygotes (FV 506 RQ). However, in the same 8 patients we detected one additional heterozygous variant of factor Leiden, and one prothrombin heterozygote (20210 GA), which had been unrecognised initially. In the remaining 32 patients we found another 4 heterozygotes (RQ) and 5 homozygotes (QQ) of factor Leiden, as well as 3 prothrombin homozygotes (20210 AA).

Regarding the analysis of MTHFR SNP in the patients group, there were 19 heterozygotes C677T and 4 homozygotes 677TT detected. Of note, only 6 among all of the patients involved in the analysis continuously received oral anticoagulant, although in 2 of them the main indication for its use was atrial fibrillation.
The distribution of pro-thrombotic alleles mentioned above, their frequency, and a comparison between the patient group and the control population are shown in Fig. 1 and in Table 1 and 2.

The assessment that focused on the co-existence of pro-thrombotic SNPs showed that only 9 of 40 (22.5\%) individuals from the patients group versus 42 of 102 (41.2\%) samples of the control population did not have any pro-thrombotic allele. The single pro-thrombotic allele (single heterozygote) was found in 16 of 40 patients (40\%) but also in 54 of $102(52.9 \%)$ control population samples. In both subgroups, MTHFR C677T was found as the most frequent single heterozygous SNP. It was present in 12 of 16 (75\%) patients with single pro-thrombotic allele and in 44 of 48 (91.6\%) respective controls. The presence of two risk-associated alleles was found in 10 of $40(25 \%)$ patients, and corresponded to 5 single homozygotes and 5 double heterozygotes (Table 2). In the control population 12 of 102 (11.7\%) samples revealed the presence of two risk-associated alleles. Three or more risk-associated alleles (pro-thrombotic homozygote combined with heterozygote, or other combinations) were found in 5 of $40(12.5 \%)$ patients and none of the controls. Among 15 individuals bearing two or more pro-thrombotic alleles, only 1 patient revealed relatively mild symptoms in ultrasound examination concerning limited reflux in intramuscular veins of the calf. The remaining 14 patients presented more extensive changes in the deep vein system, as found in the ultrasound examination.

When considering all of the mentioned pro-thrombotic SNPs, the calculated risk of DVT recurrence in individuals bearing at least one risk-associated allele $(\mathrm{OR}=2.29$; $95 \%$ CI: 0.99-5.33) was statistically significantly higher, as 
Table 2. Distribution of pro-thrombotic alleles

\begin{tabular}{|c|c|c|c|c|c|c|}
\hline \multirow[t]{2}{*}{ Tested SNP } & \multicolumn{2}{|c|}{ Total } & \multicolumn{2}{|c|}{ Single heterozygote only } & \multicolumn{2}{|c|}{$\begin{array}{l}\text { Allele combinations } \\
\text { (homozygous or combined with other } \\
\text { gene) }\end{array}$} \\
\hline & $\begin{array}{c}\text { DVT } \\
n=40(\%)\end{array}$ & $\begin{array}{c}\text { Control } \\
n=102(\%)\end{array}$ & $\begin{array}{c}\text { DVT } \\
n=40(\%)\end{array}$ & $\begin{array}{c}\text { Control } \\
n=102(\%)\end{array}$ & $\begin{array}{c}\text { DVT } \\
n=40(\%)\end{array}$ & $\begin{array}{c}\text { Control } \\
n=102(\%)\end{array}$ \\
\hline \multicolumn{7}{|l|}{ MTHFR C677T } \\
\hline CT & $19(47.5)$ & $45(44.1)$ & $12(30)$ & $44(43.1)$ & $7(17.5)$ & $1(1.0)$ \\
\hline$\Pi$ & $4(10)$ & $11(10.8)$ & - & - & $4(10)$ & $11(10.8)$ \\
\hline \multicolumn{7}{|l|}{ PT G20210A } \\
\hline GA & $1(2.5)$ & $2(2.0)$ & 0 & $2(2.0)$ & $1(2.5)$ & 0 \\
\hline $\mathrm{AA}$ & $3(7.5)$ & 0 & - & - & $3(7.5)$ & 0 \\
\hline \multicolumn{7}{|l|}{ FV R506Q } \\
\hline $\mathrm{RQ}$ & $8(20)$ & $9(8.8)$ & $4(10)$ & $8(7.8)$ & $4(10)$ & $1(1.0)$ \\
\hline$Q Q$ & $5(12.5)$ & 0 & - & - & $5(12.5)$ & 0 \\
\hline Homozygous wild & $9(22.5)$ & $42(41.2)$ & - & - & - & - \\
\hline
\end{tabular}

compared to wild genotype. However, when subtracting the minor-risk MTHFR C677T SNP the estimated risk increased 3-fold (OR $=6.11 ; 95 \%$ CI: 2.52-14.82).

\section{DISCUSSION}

In our study we have shown that the frequency of pro-thrombotic variants of main polymorphisms associated with deep vein thrombosis: FV R506Q and PT G20210A, was significantly higher in patients with recurrent DVT than in the control population. This finding, since it is similar to other reports, was not surprising. However, that risk, although considerably low, was still statistically significant when including relatively mild and indirect risk factors - the polymorphism of MTHFR (C677T) $[8,9,15,16]$. Thus, including in our model all SNPs mentioned previously, we found that $37.5 \%$ of patients with recurrent DVT, but only $12.8 \%$ of population controls, carried two or more alleles associated with increased risk of venous thrombosis. Possibly our result could, at least partially, explain the observation that the thrombosis itself increases the risk of recurrence.

Remarkably, the genetic analysis, if implemented at all, concerns only two main thrombophilic SNPs: FV R506Q and PT G20210A. The risk allele Q of FV R506Q (Leiden) SNP is found in about $5 \%$ of individuals of the Caucasian population, whereas its prevalence in DVT patients may be higher than $20 \%[4,17]$. Heterozygous patients display a 5- to 7-fold increased risk of DVT, while in mutated homozygotes it may be over a dozen-fold higher than in healthy controls. Noticeably, in some reports even 80 -fold higher risk has been suggested $[4,18,19]$. The frequency of the next polymorphism - PT G20210A - in the Caucasian population was estimated at approximately $2 \%$ [20], while in patients with DVT it may reach 6\% [21]. The heterozygous combination of PT 20210 A allele is associated with a 3-5-fold higher risk of the DVT development, whereas in 20210 AA homozygotes the chance to develop severe thrombotic complications is $8-10$-fold higher than in healthy controls (Table 3 ) $[4,16]$.

Of note, our results and some other reports indicate that the most common pro-thrombotic polymorphism in the Caucasian population is MTHFR C677T. Nevertheless, usually it is not included in genetic testing since it is considered rather a weak risk factor. This is true, especially when compared to the above-described dominant R506Q and PT G20210A SNPs. In contrast to them, recessive MTHFR $677 \mathrm{~T}$ allele is supposed to influence the risk of DVT indirectly, since its pro-thrombotic role

Table 3. Risk stratification depending on pro-thrombotic allele patterns

\begin{tabular}{lc}
\hline Pro-thrombotic allele pattern & Relative risk of DVT \\
\hline wild type homozygote & $1 \times$ \\
\hline MTHFR 677 CT/TT (with hyperhomocysteinaemia) & $1.5-2 \times$ \\
\hline F2 20210 GA & $3 \times$ \\
\hline F5 506 RQ & $5 \times$ \\
\hline F2 20210 GA or F5 506 RQ + MTHFR 677 CT/TT & $5-8 \times$ \\
\hline F2 20210 GA + F5 506 RQ & $5-10 \times$ \\
\hline F2 20210 GA + F5 506 RQ + MTHFR 677 CT/TT & $?$ \\
\hline F2 20210 AA & $8-10 \times$ \\
\hline F5 506 QQ & $12-15 \times$ \\
\hline F2 20210 GA + F5 506 QQ or F2 20210 AA + & $?$ \\
\hline F5 506 RQ & \\
\hline
\end{tabular}


is associated with hyperhomocysteinaemia and may be modified, e.g. by concomitant diseases or folate and vitamin B levels $[15,22,23]$. On the other hand, MTHFR $677 \mathrm{~T}$ allele, since present in almost $50 \%$ of individuals of the general population $[9,15]$, may slightly augment the influence of other pro-thrombotic factors, e.g. co-existing thrombophilic SNPs, major surgery or trauma, chronic venous insufficiency, oral contraceptives, cancer, etc. If such synergy occurs, the final risk may be significantly higher than estimated for single SNP.

Therefore, the current recommendations, which identify the single heterozygous thrombophilic SNP, such as not requiring any special care $[3,11,13,24,25]$, may be inaccurate [26]. Notably, this may also apply to MTHFR SNP, where large meta-analyses, by decreasing the influence of ethnic specificity, seem to underestimate the role of this polymorphism $[15,16]$.

The average cost of 6 months of DVT treatment is approximately 8000-10000 USD. When considering the management of possible complications - pulmonary embolism or venous leg ulcer -the cost of treatment is almost double. In the US the annual budget expenditure alone for DVT-associated treatment reaches approximately 6 billion USD [27-29]. In contrast, the annual costs of pharmacological prophylaxis (approximately 100-1000 USD per year, depending on the selected drug) and/or compression stockings (approximately 100-200 USD) for an individual patient do not exceed 500-600 USD. Furthermore, molecular biology methods, including genetic tests, have become much cheaper and are fully available in daily laboratory praxis. Nowadays, the cost of genetic assessment for the three mentioned pro-thrombotic SNPs ranges from 150 to 300 USD, depending on the test choice.

According to the guidelines of the American College of Medical Genetics, the indications for genetic testing in thrombophilia include patients with venous thrombosis in "atypical" localisation, at age $<50$ years, a family history of thrombotic disease, and recurrent venous thrombosis [30]. However, our data suggest that the implementation of genetic testing, but also including MTHFR C677T SNP, may provide some benefit even after the first episode of DVT. Moreover, as shown above, such a personalised approach is also economically justified.

The estimation of DVT risk in correlation to the patient genotype was based on large meta-analyses and data from a paper by Middeldorp $[4,8,16]$. In such assessment the more composite allele configurations were associated with higher risk (Table 3 ). In our analysis $40 \%$ of DVT patients were bearing a single pro-thrombotic allele. The mean risk estimated for this group, since contributed to mainly by MTHFR 677 CT heterozygous pattern, was relatively low. However, almost the same number of DVT patients (37.5\%) had composite allele configurations with the estimated mean risk above 5-8-fold. Remarkably, this estimation correlated also with patient's clinical history.
With the exception of one patient, with a relatively mild course of disease (seemingly due to chronic treatment with oral anticoagulants, which were taken to manage atrial fibrillation), other patients from that group had a more complicated history of DVT, including pulmonary embolism and leg ulceration.

Based on these retrospective data we conclude that the results of genetic tests, if available after the first episode of unprovoked DVT, could be used as a rationale to introduce or intensify the prophylaxis and thus protect from recurrence. Following such a personalised approach to genetic testing would enable risk stratification, e.g. to predict the occurrence of thrombotic complications after surgery, or in women using oral contraceptives, thus allowing more precise adjustment of the prophylaxis, including anticoagulants, to individual patient requirements and real risk of recurrence. This could be especially important, when considering the possible adverse effects of such treatment [31,32]. Moreover, there is also a psychological aspect of such assessment. A patient who is aware of the higher risk of DVT will probably better comply with proposed treatment and prophylaxis. Apart from the necessary changes in indications for use of oral anticoagulants, the results of molecular testing may be helpful as a rationale for regular control of blood homocysteine levels and prophylactic use of folic acid or vitamin B to prevent hyperhomocysteinaemia in carriers of MTHFR 677T allele [22, 23].

In summary, the results of our study suggest that genetic tests for FV R506Q, PT G20210A, and MTHFR C677T may provide some benefit for patients, especially when performed after the first episode of unprovoked DVT. However, further prospective studies in large populations are necessary.

\section{ACKNOWLEDGEMENTS}

The study was supported by an individual research grant of the Polish Society of Phlebology and LEK-AM pharmaceutical company.

The authors declare no conflict of interest.

\section{References}

1. Duru S., Keleşoğlu A., Ardıç S. Clinical update on pulmonary embolism. Arch Med Sci 2014; 10: 557-565.

2. Goldhaber S.Z., Elliott C.G. Acute pulmonary embolism: part I: epidemiology, pathophysiology, and diagnosis. Circulation 2003; 108: 2726-2729.

3. National Institute for Health and Clinical Excellence. Venous thromboembolic diseases: the management of venous thromboembolic diseases and the role of thrombophilia testing. (Clinical guideline 144.) 2012. http://guidance.nice.org.uk/CG144.

4. Middeldorp S., van Hylckama Vlieg A. Does thrombophilia testing help in the clinical management of patients? Br J Haematol 2008; 143: 321-335. 
5. Signorelli S.S., Fiore V., Puccia G., Mastrosimone G., Anzaldi M. Thrombophilia in patients with lower limbs deep veins thrombosis (LDVT). Results of a monocentric survey on 103 consecutive outpatients. Clin Appl Thromb Hemost 2013; 20: 589-593.

6. Cohen W., Castelli C., Suchon P., Bouvet S., Aillaud M.F., Brunet D., Barthet M.C., Alessi M.C., Trégouët D.A., Morange P.E. Risk assessment of venous thrombosis in families with known hereditary thrombophilia: the MARseilles-NImes prediction model. J Thromb Haemost 2014; 12: 138-146.

7. Abudureheman K., Mahemuti A., Xia Y.N., Hu X.M. Association between gene polymorphisms of methylenetetrahydrofolate reductase and plasma homocysteine in Uygur patients with venous thromboembolism. Zhonghua Xin Xue Guan Bing Za Zhi 2012; 40: 1030-1036.

8. Gohil R., Peck G., Sharma P. The genetics of venous thromboembolism. A meta-analysis involving approximately 120,000 cases and 180,000 controls. Thromb Haemostas 2009; 102: 360-370.

9. Naess I.A., Christiansen S.C., Romundstad P.R., Cannegieter S.C., Blom H.J., Rosendaal F.R., Hammerstrøm J. Prospective study of homocysteine and MTHFR 677TT genotype and risk for venous thrombosis in a general population: results from the HUNT 2 study. Br J Haematol 2008; 141: 529-535.

10. Palareti G., Legnani C., Cosmi B., Valdre L., Lunghi B., Bernardi F., Coccheri S. Predictive value of D-dimer test for recurrent venous thromboembolism after anticoagulation withdrawal in subjects with a previous idiopathic event and in carriers of congenital thrombofilia. Circulation 2003; 108: 313-318.

11. Ho W.K., Hankey G.J., Quinlan D.J., Eikelboom J.W. Risk of recurrent venous thromboembolism in patients with common thrombophilia: a systematic review. Arch Intern Med 2006; 166: 729-736.

12. Martinez C., Cohen A.T., Bamber L., Rietbrock S. Epidemiology of first and recurrent venous thromboembolism: a population-based cohort study in patients without active cancer. Thromb Haemost 2014; 112: 255-263.

13. Chong L.Y., Fenu E., Stansby G., Hodgkinson S. Management of venous thromboembolic diseases and the role of thrombophilia testing: summary of NICE guidance. Br Med J 2012; 344: e3979.

14. Marchiori A., Mosena L., Prins M.H., Prandoni P. The risk of recurrent venous thromboembolism among heterozygous carriers of factor V Leiden or prothrombin G20210A mutation. A systematic review of prospective studies. Haematologica 2007; 92: 1107-1114.

15. Krejner A., Grzela T. MTHFR polymorphisms as possible risk factors of venous thrombosis - too weak to take care, too frequent to be ignored. Phlebol Rev 2015; accepted for publication.

16. Simone B., De Stefano V., Leoncini E., Zacho J., Martinelli I., Emmerich J., Rossi E., Folsom A.R., Almawi W.Y., Scarabin P.Y., den Heijer M., Cushman M., Penco S., Vaya A., Angchaisuksiri P., Okumus G., Gemmati D., Cima S., Akar N., Oguzulgen K.I., Ducros V., Lichy C., Fernandez-Miranda C., Szczeklik A., Nieto J.A., Torres J.D., Le Cam-Duchez V., Ivanov P., Cantu-Brito C., Shmeleva V.M., Stegnar M., Ogunyemi D., Eid S.S., Nicolotti N., De Feo E., Ricciardi W., Boccia S. Risk of venous thromboembolism associated with single and combined effects of factor V Leiden, prothrombin 20210A and methylenetetrahydrofolate reductase C677T: a meta-analysis involving over 11,000 cases and 21,000 controls. Eur J Epidemiol 2013; 28: 621-647.

17. Koster T., Rosendaal F.R., de Ronde H., Briët E., Vandenbroucke J.P., Bertina R.M. Venous thrombosis due to poor anticoagulant response to activated protein C: Leiden Thrombophilia Study. Lancet 1993; 342: 1503-1505.
18. Rosendaal F.R., Koster T., Vandenbroucke J.P., Reitsma P.H. High risk of thrombosis in patients homozygous for factor $\mathrm{V}$ Leiden (activated protein C resistance). Blood 1995; 85: 15041508.

19. Cumming A.M., Keeney S., Salden A., Bhavnani M., Shwe K.H., Hay C.R. The prothrombin gene G20210A variant: prevalence in a U.K. anticoagulant clinic population. Br J Haematol 1997; 98: 353-355.

20. Eichinger S. Are B vitamins a risk factor for venous thromboembolism? Yes. J Thromb Haemost 2006; 4: 307-308.

21. Sam R.C., Burns P.J., Hobbs S.D., Marshall T., Wilmink A.B., Silverman S.H., Bradbury A.W. The prevalence of hyperhomocysteinemia, methylene tetrahydrofolate reductase C677T mutation, and vitamin B12 and folate deficiency in patients with chronic venous insufficiency. J Vasc Surg 2003; 38: 904-908.

22. Svensson P.J., Dahlbäck B. Resistance to activated protein C as a basis for venous thrombosis. N Engl J Med 1994; 330: 517-522.

23. Rosendaal F.R., Doggen C.J., Zivelin A., Arruda V.R., Aiach M., Siscovick D.S., Hillarp A., Watzke H.H., Bernardi F., Cumming A.M., Preston F.E., Reitsma P.H. Geographic distribution of the $20210 \mathrm{G}$ to A prothrombin variant. Thromb Haemost 1998; 79: 706-708.

24. Eichinger S., Weltermann A., Mannhalter C., Minar E., Bialonczyk C., Hirschl M., Schönauer V., Lechner K., Kyrle P.A. The risk of recurrent venous thromboembolism in heterozygous carriers of factor $\mathrm{V}$ Leiden and a first spontaneous venous thromboembolism. Arch Intern Med 2002; 162: 2357-2360.

25. Lindmarker P., Schulman S., Sten-Linder M., Wiman B., Egberg $\mathrm{N}$., Johnsson $\mathrm{H}$. The risk of recurrent venous thromboembolism in carriers and non-carriers of the G1691A allele in the coagulation factor V gene and the G20210A allele in the prothrombin gene. DURAC Trial Study Group. Duration of Anticoagulation. Thromb Haemost 1999; 81: 684-689.

26. Byatt K. NICE guideline has weaknesses. Br Med J 2012; 345: e5099.

27. Ashrani A.A., Heit J.A. Incidence and cost burden of post-thrombotic syndrome. J Thromb Thrombolysis 2009; 28: 465-476.

28. Bergqvist D., Jendteg S., Johansen L., Persson U., Odegaard K. Cost of long-term complications of deep venous thrombosis of the lower extremities: an analysis of a defined patient population in Sweden. Ann Intern Med 1997; 126: 454-457.

29. Duff J., Walker K., Omari A., Stratton C. Prevention of venous thromboembolism in hospitalized patients: analysis of reduced cost and improved clinical outcomes. J Vasc Nurs 2013; 31: 9-14.

30. Grody W.W., Griffin J.H., Taylor A.K., Korf B.R., Heit J.A. American College of Medical Genetics consensus statement on factor V Leiden mutation testing. Genet Med 2001; 3: 139-148.

31. Kearon C., Gent M., Hirsh J., Weitz J., Kovacs M.J., Anderson D.R., Turpie A.G., Green D., Ginsberg J.S., Wells P., MacKinnon B., Julian J.A. A comparison of three months of anticoagulation with extended anticoagulation for a first episode of idiopathic venous thromboembolism. N Engl J Med 1999; 340: 901-907.

32. Palareti G., Leali N., Coccheri S., Poggi M., Manotti C., D’Angelo A., Pengo V., Erba N., Moia M., Ciavarella N., Devoto G., Berrettini M., Musolesi S. Bleeding complications of oral anticoagulant treatment: an inception-cohort, prospective collaborative study (ISCOAT). Italian Study on Complications of Oral Anticoagulant Therapy. Lancet 1996; 348: 423-428. 